\title{
Impact of Herbal Medicine on Restoration of Post Menopausal Women's Health
}

\author{
Anjum $A^{1}$, Tabassum $K^{2 *}$ and Banu $S^{3}$ \\ ${ }^{1}$ Associate Professor, Department of Surgery, Govt Unani Medical College, \\ Bangalore, India \\ ${ }^{2}$ Reader, Department of OBG, National Institute of Unani Medicine, Bangalore, \\ India \\ ${ }^{3}$ Principal, Govt Unani Medical College, Bangalore, India \\ *Corresponding Author: Tabassum K, Reader, Department of OBG, National \\ Institute of Unani Medicine, Bangalore, India.
}

\author{
Received: March 11, 2020 \\ Published: October 28, 2020 \\ (C) All rights are reserved by Tabassum K., et \\ al.
}

\begin{abstract}
Menopause is a natural biological process occur after 40 years in every women's life. But the physical symptoms, such as hot flashes, and emotional symptoms of menopause may disrupt their sleep, lower energy or affect emotional health. The mean age of menopause is 49.4 years and 130 million Indian women are expected to live beyond menopause into old age by 2015 . In India, $19 \%$ of women age 40 - 41 have already reached menopause, and the incidence of menopause increases rapidly after 41 . By the age of 48 - 49 years two third of women are in menopause. So, the number of women in menopause is increasing with their life expectancy and also with reported problems. Therefore, quality of this population becomes a major issue and understanding of menopause is very important issue. Long term use of HRT (Hormone Replacement Therapy) has been associated with increased risks for venous thromboembolism, coronary heart diseases, stroke and breast cancer. In classical unani text, though menopausal transition is not mentioned as such, but its clinical features can be correlated with complications occurring due to Ehtebase haiz (Amenorrhoea). There are many effective treatments available, from lifestyle adjustments to hormone therapy. In unani system of medicine, many herbal medicines are documented to alleviate these symptoms. Herbal medicines include Asgandh, Soya, Alsi, Todari, Aslasoos, etc. This review paper focuses on herbal medicines which are useful in menopausal syndrome.
\end{abstract}

Keywords: Menopause; Biological Changes; Unani Herbal Medicine; Management

\section{Introduction}

The purpose of this article is to review the scientific literature related to physio-pathological manifestations and herbal product for the treatment of menopause related symptoms. Menopause is not a disease and is a balance deficiency only. It occurs in women's lives as part of normal aging. It is a transition from reproduction to non-reproduction occurs between the ages of 40-60 years [1]. Menopausal symptoms may manifest themselves 2 or 3 years before the actual menopause starts and continue for 2-5 years [2,3].
Women all over world now must spend almost $1 / 3^{\text {rd }}$ of their lives in menopause, because of increasing life expectancy. In India, the mean age of menopause is 49.4 years and 130 million Indian women are expected to live beyond menopause into old age by 2015 [4]. The incidence of menopause increases rapidly after 41 years. By the age of 48 - 49 years, two third of women are in menopause [1].

Menopause occurs because of cessation of ovarian function as they stop to produce hormones - oestrogen and progesterone. Premature menopause occurs before the age of 40 years and if 
menopause occur beyond 55 years it is called delayed menopause. Women who have a family history of premature menopause are genetically more susceptible to early onset of menopause. Premature menopause can also result from Hystero-Ovariotomy. Hysterectomy alone does not cause menopause. Some types of cancer radiation and chemotherapy treatments can induce menopause. Certain autoimmune disorders, such as rheumatoid arthritis and Graves' disease can lead to premature menopause. Genetic disorders such as Turner syndrome that causes ovarian abnormalities can also predispose to early menopause.

Although symptoms of menopause may last long after the menopausal transition is complete. During menopause major physiological, psychological and gynecological changes occur [3,5]. Many women during menopausal transition have few or no symptoms that can be ignored by her and her family members, but over $50 \%$ of women have significant or even disabling symptoms, which are alarming to both the women and their families. Vasomotor symptoms include hot flushes, night sweats, insomnia, mood swings, palpitation and parasthesia, psychological features include anxiety, headache, irritability and depression. Urinary and genital features are frequency of micturition, menstrual abnormalities, dryness of vagina, atrophy of the genital organs, dyspareunia and sexual dysfunction [5-7] and general features include backache, arthritis, dryness of skin, brittleness of hairs and weight gain. Complications of Menopause include Hypertension, Diabetes Mellitus, Cardiovascular Diseases, Osteoporosis, etc. [8-10] all these symptoms are due to deficiency of estrogen.

According to Unani System of Medicine menopause is a combined state of weakness of Tabiyat (nature) and Quwat-e-Dafai (expulsive power) of uterus that causes deposition of the waste substance in the body, as the age advances almost all Qua (powers) decline. This decline also affects the Quwat-e-Dafia of uterus. Usually the uterus expels wastes from the body monthly in the form of menstruation. Since the women being of Barid Ratab Mizaj (Cold and moist) produce more wastes and weakness of this power cause deposition of wastes towards the uterus. The accumulated waste may be either Ghaleez (Viscous) or Raqeeq (Dilute) and by nature may be irritative. Overall these wastes admix with blood and get accumulated in cavities. In this way they disturb the Mizaj (Temperament) of blood primarily and then of organs. The blood admixes with these wastes can't be utilized for nutritive purpose satisfactorily [11].
The waste substance present in potential spaces stimulate Tabiyat, which then expel them towards the surface where they are responsible for various cutaneous manifestations associated with menopause such as dry and itchy skin, and acne. More over dilute components of the wastes get dissolute leaving viscous components. Hence, Imtilae Suada (accumulation of black bile) occurs. Dominance of this abnormal Sauda is responsible for various vasomotor and psycho-physiological manifestations. Sign and symptoms of Zabool (general weakness) are manifested as defective functions. Presence of wastes causes suppression of Haratee Ghareezia (heat) in the body that leads to organic digestion declines [12-14].

Assessment of Follicular Stimulating Hormone (FSH) and Luteinizing Hormone (LH) is recommended to diagnose and confirm menopausal syndrome. Sedatives and tranquilizers along with Hormonal Replacement Therapy (HRT) are the choice of treatment $[15,16]$. These are effective in the treatment of menopausal symptoms and it is an accepted treatment since many years [17-21].

Fortunately for the management of menopausal sign and symptoms Unani physicians have mentioned several drugs helps in strengthening and rejuvenation the female reproductive organs, which regulate hormones and calm emotions [22,23]. They also contain Antioxidants and Phyto-oestrogens, which are helpful in maintaining the hormonal balance without any side effects and are helpful in the management of geriatric problems. Unani compound preparation such as Majoon Najah, Majoon Falafasa, Khameera Marwarid, etc. are useful in Balghami and Saudavi (Phlegmatic and Melancholic) diseases and nervous disorders which expel the wastes of the body and restore normal body's functions [24].

Many women accept menopausal syndrome as a normal part of their life and they may not believe in the treatment. Improved understanding of the pathophysiology of the syndrome may result in the discovery of effective treatment regime. That will lead to reduction in the social and medical consequence of menopausal syndrome [25].

Numerous studies have demonstrated the ability of herbal medicines to improve quality of life through increased stamina, mental agility, reduced susceptibility to stress and infection and reduction of fatigue and depression. It may be particularly beneficial for the treatment of menopausal syndrome. Phyto-oestrogens stimulate the production and adjust the level of estrogen and pro- 
gesterone in the body. They found in Soya, oats, carrots, cherries, garlic, onion, coconut, cumin, beans, wheat, lemon, licorice, peppermint, peas, tomatoes, brown rice, sunflower seeds, sesame, apple, orange, grapes, etc. In humans, gastrointestinal tract enzymes convert isoflavines into heterocyclic phenols that have a structural similarity to estrogen. The beneficial effects of soya supplements in postmenopausal women have been attributed to these isoflavines [26-29].

Compound formulations useful in menopausal symptoms

- Hot flushes: Lifestyle changes include dressing and eating balanced diet; avoid being too warm and spicy foods and caffeine, sleeping in a cool room, and reducing stress, deep breathing and stress reduction techniques. About $75 \%$ women will experience hot flashes; $5 \%$ of women will have severe hot flashes. This may lead to embarrassment and physical discomfort [21]. Commonly used compound formulations are Khameera Abrasham, Khameera Marwarid which reduces the hot flushes and relief the symptoms $[24,30]$.

- Mood swings: Lifestyle behaviors, including getting enough sleep and being physically active, relaxation exercises, antidepressant or anti-anxiety drugs are more useful like Majoon Najah, Majoon Falasafa, etc. These formulations are useful in Saudavi (Melancholic) diseases, which expels the abnormal Sauda (Black bile) from the body and rejuvenate the body [24]. The ingredients of Majoon Najah having the properties of Mufarih (Exhilarant), Muhallil (Anti-inflammatory), Muqavi Qalb, Dimagh, Meda and Ahsha (Tonic to Heart, Brain, Stomach and Organs), Mushil Balgham, Safra and Sauda (Purgation of Phlegm, Yellow and Black bile), Mulatif and Taqiyae Sauda (Elimination of black bile) and Jali (Detergent). They also contain phytoestrogens, which are used in the management of geriatric problems. It has antioxidant and rejuvenating properties also.

- Insomnia: Insomnia is a common problem for perimenopausal women, and lack of sleep aggravates stress, memory loss, depression and physical discomfort. Consumption of low-fat or fat-free food varieties at bedtime and hot shower or bath immediately before going to bed are helpful. Barshasha [30] means immediate relief as it gives immediate relief, hence it is useful in insomnia and other anxiety disorders.
- Memory problems: Mental exercises and lifestyle behaviors, especially getting enough sleep and being physically active. Unani compound formulations like Itriphal Ustukhuddus, Itriphal Kishneezi, etc. are helpful in memory loss [24].

- Heart diseases: Women between ages of 55-70 years are at risk of heart diseases. Smoking is linked to a decline in estrogen levels. Women who smoke reach menopause about 2 years earlier than nonsmokers. Smoking doubles a woman's odds of developing heart disease and is a major risk factor for osteoporosis [31]. Unani compound formulations like Khameera Marwarid, Khameera sandal, Khameera Goazaban, Khameera Abresham, etc. [24] are helpful for primary prevention of heart diseases.

- Palpitation: Palpitation is common symptom among otherwise healthy perimenopausal women. Khameera Goazaban, Khameera Abresham [22] are useful in the management of palpitation.

- Depression and anxiety: Hormonal changes, aging, personal concerns, loss of sleep, inadequate nutrition, problems with memory, and other physical complaints can fuel feelings of frustration and depression, and new concerns about health can lead to anxiety [32]. Compound formulation Majoon Falasafa [24] is recommended for all anxiety disorders.

- Vaginal dryness: This uncomfortable symptom increases susceptibility to infection and may have a negative impact on sexual experience with both physical and emotional ramification. Vaginal lubricants and moisturizers are useful. Topical emollient therapies also useful such as Marham Dakhaliyun [22]. Vitamins A and E, aloe vera is more useful as it gives soothing effect on vaginal surface. Calendula is recommended to counteract vaginal dryness. A solution of calendula can be used as a douche [33].

- Menstrual irregularities: Qurs Habis, Safoof Habisuddam, Sharbat Anjabaar, etc. are very good unani compound formulation to stop any type of menstrual bleeding during menopausal transition, since it has astringent and cooling proprieties [24].

- Urinary symptoms: Frequency and dysuria are the common symptoms during menopausal period [34]. Majoon Masikul boul is a drug of choice for urinary problems [24] as it reduces the frequency of urination. 
Herbs useful for menopausal symptoms

\section{Asgandh (Withania somnifera Linn)}

Asgandh has adaptogenic effects and is a safe general tonic that normalizes body functions; reduce the stress hormones that often increase in depression. It is also a nervine tonic, mild sedative and a tonic for the immune system. It improves health and stamina. It may be useful in the prevention and treatment of cancer [22].

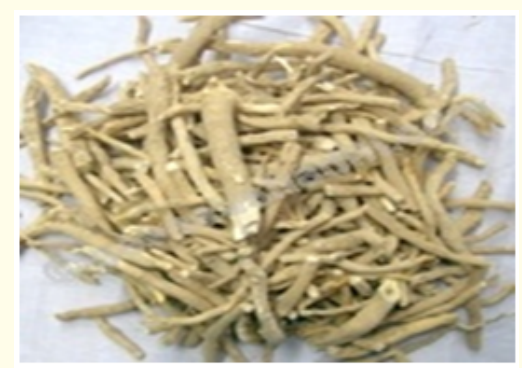

Figure 1

\section{Babuna (Matricaria chamomilla Linn.)}

The genus Matricaria is derived from the Latin word matrix, means "womb," most likely because chamomile is widely used to treat sleep and anxiety disorders related to Menopausal syndrome. Chamomile has been found to contain strong antispasmodic, analgesic, sedative and anti-inflammatory properties and is particularly effective in treating stomach and urinary symptoms. It reduces cramping and spastic pain in the bowels and relieves excessive gas and bloating in the intestines. It is often used to relieve irritable bowel syndrome, nausea, and gastroenteritis. Chamomile is also an excellent calming agent, well suited for irritable patients [22].

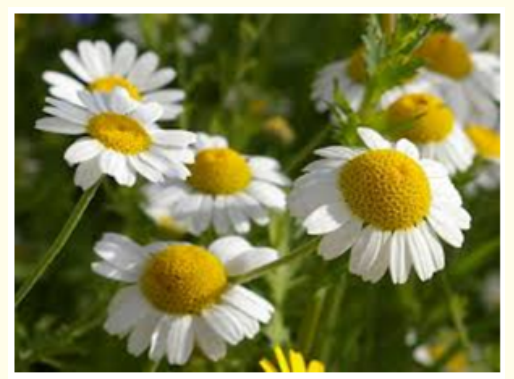

Figure 2

\section{Ustukhuddus (Lavandula angustifolia Linn)}

A herb rather than an essential oil, is used to reduce depression. Lavender is a strengthening tonic to the nervous system and is useful for headaches and migraine, especially those associated with menopause [22].

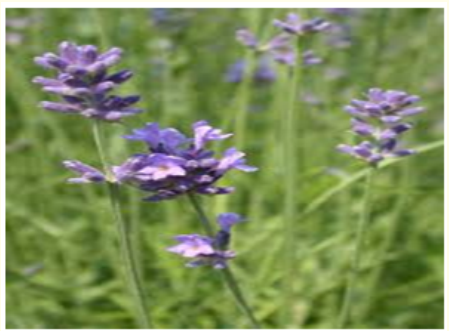

Figure 3

\section{Evening primrose oil}

Evening primrose oil comes from the seeds of the yellow primrose, is a wildflower. The seeds contain oils rich in linolenic acid and $\gamma$-linolenic acid, precursors of prostaglandin E. Disorders for which evening primrose oil have been tested include atopic dermatitis, rheumatoid arthritis, mastalgia, fibroadenoma of breast, premenstrual syndrome and menopausal hot flashes [35,36].

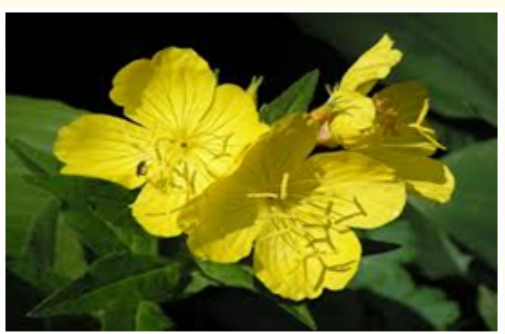

Figure 4

\section{Trifoliumpretense Linn}

It contains all the four specific isoflavones that have been shown to be most beneficial to the human body genistein, deidzein, formonentin and biochanin A. Red clover $80 \mathrm{mg}$ daily has been clinically proven to reduce night sweats by $75 \%$ and can also relieve insomnia in menopausal women, even when they are not suffering with night sweats. It also has an important role for women who do not 
have obvious symptoms, as it seems to have a protective effect on the heart and bones [37].

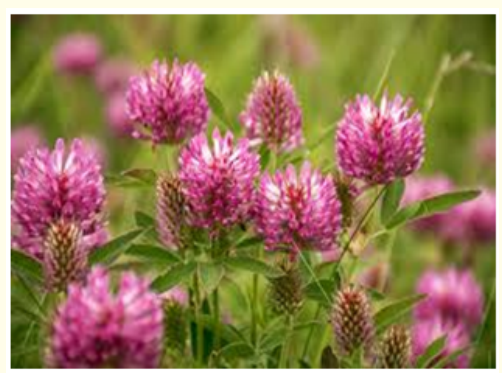

Figure 5

\section{Turbud (Tribulus terrestris Linn)}

It relaxes smooth muscles and improves the circulation in the genital organs of both men and women, leading to improved sexual response. For women, the hormone balancing effects of Turbud make this a suitable herb for premenstrual syndrome and menopausal symptoms. Tribulus is also a popular anabolic supplement among body builders who use it to lower cholesterol and to increase lean muscle mass. Tribulus terrestris has anti-bacterial and anti-viral properties that may be used to treat herpes and other viral infections [38].

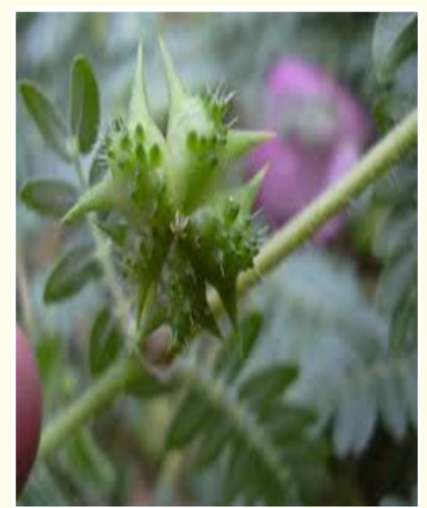

Figure 6

\section{Assalusoos (Glycyrrhiza glabra Linn)}

is a perennial herb, mostly grown in Greece, Turkey and Asia. It is also known as sweet root. Licorice contains numerous active compounds and over 40 flavinoids. Those with potential benefits for women in menopause are saponins and phytoestrogens [39]. The active substances work similar to some of the anti-depressant drugs on the neurotransmitter serotonin, which can help women with mood swings and menopausal depression. Licorice contains specific flavinoids that have a weak estrogen-like activity, which help with hot flashes. There is also a de-glycyrrhizinated which is useful in the treatment of ulcers and some other gastric ailments. Another content glycyrrhizin is useful in nervous disorders. The licorice herb may be used for night sweats but should not be taken for long-term or those having Hypertension [39].

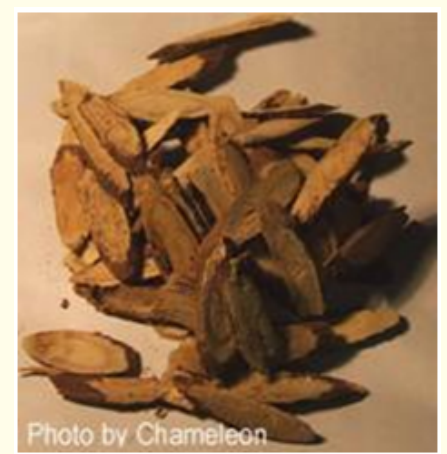

Figure 7

Diet

Balance calorie intake and eating frequent small meals rather than larger ones is helpful. Drinking cold drinks frequently has been reported helpful for some women, as it temporarily lowers body temperature and may reduce hot flushes.

\section{Soya products}

Contains phyto oestrogens in large quantity. Phyto-oestrogens are currently the most popular alternative to hormone replacement therapy $[40,41]$.

\section{Vitamin D}

Vitamin D is an essential building block for a healthy body. It promotes healthy bone regeneration, normal cell growth and hormonal balance, which are all important for menopausal women. Vitamin D is often referred to as the Sunshine Vitamin as body produces it in response to sun exposure. As women age is advances their ability to absorb vitamin D decreases, increase the risk of bone density loss. This makes the need to incorporate vitamin D in diet that much more critical. Studies also suggest that, vitamin 
D may help control feelings of sadness and anxiety, which are common symptoms of menopause [42].

\section{Antioxidants [43]}

Free Radicals are an important factor in the ageing process and are constantly formed in most cells and tissues. They are typically scavenged by antioxidants such as vitamins A, C and E; these antioxidants may help to support the body from free radical damage. Vitamin C, E and B-complex, zinc, iron and copper maintain a healthy immune system, selenium and vitamins $\mathrm{A}, \mathrm{C}$ and $\mathrm{E}$ act through their antioxidant action, while zinc, magnesium and copper act as co-factors in antioxidant enzymes.

\section{Conclusion}

A goal of treatment during menopause is to minimize discomfort from menopausal symptoms. Menopausal symptoms are common, but vary by BMI, ethnicity, smoking status, and other lifestyle variables. The results of the WHI (Women's Health Initiative) have altered the assumption that HRT could reduce cardiovascular risks that rise after menopause. With the decline in recommendation for HRT, the potential role of phytooestrogens and phytochemicals in controlling menopausal symptoms is of increased interest. Vitamins and phytoestrogens may be beneficial, which can reduce symptoms. It is reasonable to test the potential maximal effect that can be achieved by combining the wide variety of foods containing phytoestrogens with supplements such as soya.

The combined effect of these foods needs to be evaluated. Combining dietary approaches with other lifestyle approaches such as physical activity and light weight clothing is also helpful to alleviate symptoms of menopause.

\section{Bibliography}

1. "Practice committee of the American Society for reproductive". The Journal of Menopausal Transition, Fertility and Sterility 10 (2016): 86.

2. Dutta DC. Text Book of Gynecology, New central book agency, Calcutta, India (2000): 48-51.

3. Jeffcoat's principles of Gynecology, Pratap Kumar and Narender Malhotra, Jaypee Brother Medical publishers, $7^{\text {th }}$ edition (1986): 862-873

4. Kumar P and Malhotra N. Jeffcoat's Principles of Gynaecology, Jaypee publishers, New Delhi (2008): 862.
5. Seven teachers, text book of gynaecology (2010): 41-50

6. Text Book of Gynecology, Berek and Novak's Lippin Cott Williams and Wilkins, $14^{\text {th }}$ edition (2007): 1323-1330.

7. Mangione CM., et al. "NIH state of the science conference statement on management of menopause related symptoms". NIH Consensus State Science Statements 22.1 (2005): 1-38.

8. Nelson HD., et al. "Management of menopause related symptoms". AHRQ Evidence Report/ Technology/Assessment 120 (2005): 1-916.

9. Buist DS., et al. "Use of alternative therapies for menopausal symptoms results of a population based survey". Obstetrics and Gynecology 100 (2002): 18-25.

10. Khan. Al Umoor-Al Tibiya, Aizaj publication, New Delhi (2000): 46-56.

11. Jurjani AH. Tarjumae Zakheera Khwarzam Shahi (Trans: Khan HH). New Delhi: Idara Kitabus Shifa (2010) 599-600.

12. Razi ABZ. Kitabul Hawi. CCRUM: New Delhi 9 (2001): 151-158.

13. Ibn Sina, Al Qanoon fil Tib, Volume $2^{\text {nd }}$, Idrae Kitabushifa, New Delhi (2010): 1095-1097.

14. Wassertheil-Smoller S., et al. "Effect of estrogen plus progestin on stoke in post-menopausal women, The Women's Health Initiative-Randomized controlled trial". JAMA 289.20 (2003): 2673-2684.

15. Anderson GL., et al. "Effects of conjugated equine estrogen in post-menopausal women with hystectomy, The women's Health Initiative-Randomized controlled trial". JAMA 291.14 (2004:)1701-1712.

16. Writing Group for the Women's Health Initiative Investigators. "Risks and benefits of estrogen plus progestin in healthy postmenopausal women: principal results from the Women's Health Initiative randomized controlled trial". JAMA 288 (2002): 321-333.

17. Birkhauser MH., et al. "Updated practical recommendations for hormone replacement therapy in the peri- and post menopause". Climacteric 11 (2008): 108-123.

18. Newton KM., et al. "Use of alternative therapies for menopausal symptoms results of a population-based survey". Obstetrics and Gynecology 100.1 (2002): 18-25.

19. Dawn C.S Text book of Gynecology, Dawn books, Calcutta, $10^{\text {th }}$ edition (1990): 81-82. 
20. Rossow JE., et al. "Risks and benefits of estrogen plus progestin in healthy postmenopausal women principal results from the women's Health Initiative-Randomized controlled trial". JAMA 288 (2002): 321-333.

21. Mohd Hakeem, Bustanul Mufradat, Lucknow (2013): 20-100.

22. Syed Safiuddin, Advia Mufradat, 16.31 (2012): 279.

23. Kabiruddin, Bayaz Kabir, Maktaba Naimia, U.P 1 (2011): 143.

24. National Center for Complementary and Alternative Medicine (2010).

25. Lethaby AE., et al. "Phytoestrogens for vasomotor menopausal symptoms". Cochrane Database of Systematic Reviews 4 (2007): 24-27.

26. Setchell Setchell., et al. "Mammalian ligans and phytoestrogens: recent studies on their formation, metabolism, and biological role in health and disease". In: Rowland I., Editor, Role of the gut flora in toxicity and cancer, Academic Press, London (2014): 315-345.

27. Kuiper Kuiper G., et al. "Interaction of estrogenic chemicals and phytoestrogens with estrogen receptor beta". Endocrinology 139.10 (2000): 4252-4263.

28. A Cassidy., et al. "Biologic effects of a diet of soy protein rich in isoflavones on the menstrual cycle of premenopausal women". The American Journal of Clinical Nutrition 60 (2018): 333-340.

29. Ghani HN. Khazainul advia YNM. Delhi: Idara kitabul shifa New Delhi (2011): 362.

30. Salpeter SR., et al. "Coronary heart disease events associated with hormone therapy in younger and older women. A metaanalysis". Journal of General Internal Medicine 21 (2006): 363366.

31. Butt DA., et al. "Gabapentin for the treatment of menopausal depression and anxiety: a randomized controlled trial". Menopause 15 (2008): 310-318.

32. Van der Laak JA., et al. "The effect of Replens on vaginal cytology in the treatment of postmenopausal atrophy: cytomorphology versus computerized cytometry". Journal of Clinical Pathology 55 (2002): 446-451.

33. Notelovitz M. "Urogenital aging: solutions in clinical practice". International Journal of Gynecology and Obstetrics 59 (2007): S35-39.
34. Kleijnen Kleijnen J. "Evening primrose oil: currently used in many conditions with little justification". British Medical Journal 309.1 (2017): 824-825.

35. Lucero MA and McCloskey WW. "Evening primrose Alternatives to estrogen for the treatment of hot flashes". Annuals of Pharmacotherapy 31 (2011): 915-917.

36. Geller SE and Studee L. "Contemporary alternatives to plant estrogens for menopause”. Maturitas 55 (2010): 3-13.

37. Center for Nutrition Policy and Promotion (CNPP), United States Department of Agriculture (2015): 34-46.

38. Dietary Guidelines for Americans (2018).

39. K Elkind-Hirsch. "Effect of dietary phyto-estrogens on hot flushes: Glycyrrhiza glabra Linn for traditional estrogen replacement therapy?" Menopause 8.3 (2015): 154-156.

40. Knight Knight DC., et al. "Effects on menopausal symptoms and acceptability of isoflavone-containing soy powder dietary supplementation". Climacteric 4 (2001): 13-18.

41. Cashman K. "Diet, nutrition and bone health". Journal of Nutrition 137 (2018): 2507-2512.

42. Campbell $\mathrm{W}$ and Leidy H. "Dietary protein and resistance training effects on muscle and body composition in older persons". Journal of the American College of Sports Nutrition (2017): 26-30.

43. Allen L. "How common is vitamin deficiency?" American Journal of Clinical Nutrition (2019): 34-37.

\section{Assets from publication with us}

- Prompt Acknowledgement after receiving the article

- Thorough Double blinded peer review

- Rapid Publication

- Issue of Publication Certificate

- High visibility of your Published work

Website: www.actascientific.com/

Submit Article: www.actascientific.com/submission.php Email us: editor@actascientific.com

Contact us: +919182824667 